\title{
DIÁLOGOS E ENGAJAMENTO EM O CANTO DO SOL: REFLEXÕES SOBRE A LITERATURA DE OLNEY SÃO PAULO
}

\author{
Claudio Cledson Novaes \\ Mírian Sumica Carneiro Reis
}

RESUMO: Neste artigo, analisamos a produção literária do escritor e cineasta baiano Olney São Paulo, discutindo as relações entre a linguagem literária e cinematográfica em sua obra, privilegiando a discussão do engajamento cultural, através da leitura de sua narrativa de temática sertaneja, destacando do livro A Antevéspera e o Canto do Sol o conto "A Rebelião e o Vento".

PALAVRAS-CHAVE: Literatura, Cinema, Diálogo, Engajamento

ABSTRACT: In this paper, we analyze the literary production by Olney São Paulo, writer and film maker of Bahia, discussing the relationships between the literary and cinematographic languages in his work, privileging the discussion about the cultural engagement, through the lecture about Olney São Paulo's narrative with country theme, specifically the short history "A Rebelião e o Vento", part of the book A Antevéspera e o Canto do Sol.

KEYWORDS: Literature, Cinema, Dialogue, Engagement

\footnotetext{
* Universidade Estadual de Feira de Santana (UEFS/FAPESB). Doutor em Ciências da Comunicação (ECA-USP). Professor Titular do Departamento de Letras e Artes (DLA): cledson@uefs.br

** Fundação de Amparo a Pesquisa do Estado da Bahia (FAPSEB). Doutoranda em Ciência da Literatura (UFRJ): miriansumica@gmail.com
} 
A obra de arte deita raizes profundas no que se convencionou chamar "realidade" (natural, psíquica, histórica), constitui uma dessas evidências fulgurantes que deveriam dispensar discurso demonstrativo, bastando-lhe a constatação a olho nu

(BOSI, 1996: 27).

Discutimos a problemática do neo-realismo na obra de Olney São Paulo, segundo a concepção de que a importância do seu engajamento não está meramente relacionada ao conteúdo social dos textos. A narrativa neo-realista engaja na ficção a vontade de potência da mimese ativista na perspectiva de visibilidade do real, mas engaja também o jogo formal para novas percepções, que, segundo Gilles Deleuze (2005: 11), ao definir o relato neo-ralista no cinema, diz ser a "ascensão de situações puramente óticas (e sonoras, embora não houvesse som sincronizado no começo do neo-realismo), que se distinguem essencialmente das situações sensóriomotoras da imagem-ação do antigo realismo". Neste sentido, a literatura do século XX desperta no leitor as relações propositais e inesperadas com o diálogo entre os códigos tradicionais da linguagem verbal e novos simulacros de realismo da linguagem visual do cinema.

$\mathrm{O}$ agenciamento do real na dizibilidade e visibilidade ficcionais espelha os interesses éticos e estéticos de escritura engajada na comunicação de significados preparados para a resposta do público leitor ou espectador do texto. O sentido enreda-se na forma da linguagem simulando na escritura os aspectos sociais e culturais agenciados em imagens que suplementam o território da estética com as questões geo-políticas do território identitário vislumbrado na representação. Portanto, as análises da narrativa 
neo-realista remetem necessariamente à investigação de pressupostos do engajamento autoral da obra sobre um determinado imaginário tomado em sua referência temática, em seus personagens e seus enredos épicos ou dramáticos. Segundo Silviano Santiago (2004: 111), a partir dos anos 1940, com o adensamento dos recursos da indústria cultural e da comunicação de massa, até mesmo a literatura mais introspectiva, que desejava contraporse ao romance de denúncia social do regionalismo de 1930, "se dá em linguagem cinematográfica”. Para o crítico:

Trata-se, porém, de um "cinema íntimo", onde os olhos do autor são a câmara que se volta para dentro. Os escritores amantes do cinema se voltam extrovertidamente para o cinema, apoiando-se na sua técnica narrativa para compor os textos propriamente literários.

Neste texto, discutimos a relação entre a escrita literária e o estilo do "cinema íntimo" nos contos de Olney São Paulo, autor ainda pouco estudado no cenário cultural brasileiro, mas de fundamental importância pela contundência política com que o estilo e a temática da sua obra incorporaram traços da tradicional narrativa regionalista, após a explosão de imagens do regionalismo de 1930 com o diálogo enviesado que os cineastas modernos estabelecem com esta tradição literária.

O neo-realismo permeado de simbolismos e alegorias radicais de Olney o levou inclusive ao traumático e tortuoso processo da censura do regime militar, que considerou o seu filme Manhã Cinzenta (1969), extraído do conto homônimo (1966) de sua autoria, como uma mensagem subversiva. Este fato político é considerado por alguns críticos e historiadores da arte como o estopim do recalque cultural da sua obra bem como um contributo para a sua morte física prematura.

Neste artigo, recortamos da obra de Olney São Paulo um encontro estilístico entre a literatura e o cinema, considerando a sugestão de uma interface que, apesar de ser bastante suscitada, requer sistematização crítica e bases confiáveis de argumentação teórica para se investigar os efeitos da relação comparatista entre as duas linguagens. Tal metodologia implica em problemas teóricos para a história literária e para a cinematografia brasileiras, assim como implica em promover revisões do cânone e de categorias estéticas agenciadas pelo crítico, quando retomamos as adaptações da literatura nacional no cinema, investigando outras formas de tensão entre os estilos, as gerações, as linguagens e as políticas culturais envolvidas. 
Duas perguntas são fundamentais para investigarmos o fenômeno comparativo através da obra regionalista de Olney São Paulo: em que medida seus contos sertanejos escritos nos anos 1960/1970 são desdobramentos epigonais do regionalismo de 1930 e como se dá o diálogo literatura/ cinema presente nas produções de Olney com a linguagem do cinema novo na escritura que se realiza na nova tradição da literatura cinematográfica.

Para investigarmos essas questões é necessário verificarmos o contexto da produção do autor. Nos primeiros 50 anos do século XX, os recursos estilísticos do cinema na literatura apontavam para a novidade da imagemmovimento, que contaminava os recursos narrativos literários modernos. Houve um longo movimento de adaptações da literatura popular do romance realista e naturalista no cinema, que consolida o sucesso do modelo clássico de cinema, ao confluir os melodramas popularizados na literatura para as expectativas do público diante da tela. Mas, a partir dos anos 1950, surge novo movimento de diálogo na montagem cinematográfica do texto literário, bem como na forma do texto literário dialogar com a linguagem do cinema

Relacionar cinema e literatura é importante para compreendermos o ponto de tensão dentro do pensamento moderno, porque sugere que o sentido polifônico das narrativas ficcionais favorece o diálogo da linguagem literária com a imagem em movimento do cinema, o que é intensificado como estratégia da indústria cultural, principalmente após a crise da representação no pós-guerra. Os escritores e cineastas se defrontam com vários dilemas sociais, econômicos, políticos e psicológicos, entranhados na forma estética e no engajamento ético, como um jogo entre o sentimento local e o desenraizamento global que o cinema vem consolidar enquanto tradução da linguagem verbal literária em movimentos técnicos da imagem.

No Brasil, este sistema de relações mobiliza toda uma geração de escritores e diretores envolvidos direta e indiretamente nos movimentos nacionalistas do chamado regionalismo sertanejo, como é o exemplo recortado de Olney São Paulo. Não só pela questão de engajamento político de viés internacional, mas também pela disponibilidade temática e modernismo crítico em explicitar externa e internamente as transformações e perspectivas do contexto social brasileiro exposto através dos personagens literários, muitos deles em crise de valores e psicologicamente alterados, a obra de Olney São Paulo reflete um encontro mais substancial entre o escritor e o cineasta burguês e uma forma literária e cinematográfica nacional-popular menos estereotipada do que a tradição melodramática 
do realismo e naturalismo clássicos. Fragmentos são transformados em totalidades pela técnica de montagem e pela linguagem poética concreta que lança novos olhares sobre os conteúdos tradicionais, por exemplo, os temas regionalistas.

Os escritores e cineastas lançam mão de procedimentos que deslocam as fronteiras entre as linguagens, as ciências, os estilos e os próprios artefatos artísticos: livro, roteiro, filme, arranjos, colocando um ponto de tensão criativa entre a literatura o cinema, o que intensifica a negação do herói identificado com o épico moderno, para espelhar novo gosto da classe média, que se distinguia cultivando a literatura e também a nova linguagem do cinema, antes uma arte voltada para divertir a massa, portanto questionada como instrumento de formação. O novo caminho do diálogo busca formas de narrar que desestabilizem a imagem-movimento clássica, que foi o fruto cinematográfico do gosto mediano, desencadeando na literatura moderna e no cinema moderno o que Gilles Deleuze (1992: 78) chamará de imagemtempo, que faz o espectador pensar sobre o movimento porque dele nasce "uma nova raça de personagens".

Inserida historicamente neste contexto social e cultural de transformação dos diálogos entre literatura e cinema e da nova formação política dos intelectuais e artistas engajados no discurso nacional-popular modernista e pós-modernista, encontramos a obra literária de Olney São Paulo, a qual se compõe de alguns contos sertanejos publicados na segunda parte do seu livro A Antevéspera e O Canto do Sol (1969).

Na leitura desta obra de Olney podemos articular um duplo movimento: primeiro, o temático, a tradição do conto regionalista sertanejo com representações da vida e mitos do sertão; segundo; o formal, a investida sobre as tensões da linguagem para flagrar na forma a simulação de um tema da subalternidade. Esta experiência de jogo entre forma e conteúdo é muito produtiva na investigação do cenário político e cultural da época que buscava encenar os temas numa linguagem pobre que reforçasse as características da realidade representada. Na literatura, essa investigação dá-se pelo aprendizado modernista da sociolingüística que enfatiza as construções populares da língua na escritura literária; no cinema dá-se pela reversão da gramática clássica com a invasão de elementos diretos da realidade: a luz, os sons e a câmera na mão. Na construção do enredo das narrativas, Olney absorve da tradição regionalista o tema já valorizado pelo romance de 1930 e reinsere na temática as perspectivas singulares da sua geração, problematizando a condição do escritor que absorve a memória tradicional em 
novas condições intelectuais. O autor utiliza os argumentos da literatura regional e com isso mantém a feição épica dos contos de cangaço, e dando ao relato o caráter da experiência, com o sentido de narrador moderno dado por Walter Benjamin (1993: 198), ao falar da "experiência que passa de pessoa a pessoa" como fonte de recorrência do narrador.

O movimento de memória dentro e fora do modernismo resvala no épico do conto de Olney São Paulo, em sua narrativa de personagens construídos num crescente de movimentos e ações, tanto físicas, quanto morais e psicológicas, atribuídas aos personagens. Neste movimento está presente a crítica política e ideológica do movimento nacional-popular sobre os fenômenos sociais nordestinos: o cangaço, a fome, o beatismo e toda a violência do sertão como conseqüência do latifúndio e da ordem político-econômica de concentração agrária. Na exposição do dilema social aparecem as contradições dos personagens.

No conto A Rebelião e o Vento, a beleza poética do título se complementa na montagem paulatina de tropos crescente. Mas, a expectativa do leitor é suscitada e desmontada com cortes cinematográficos neste conto de tema tradicional do sertão. O sertanejo Pedro Macário de Oliveira e o coronel Tibúcio formam a estrutura clássica da luta entre opostos, recorrendo à sensibilidade política do leitor em cenas dinâmicas que suscitam uma interlocução inexorável com a narrativa que aguarda respostas do leitor para dar continuidade à seqüência. O sertanejo Pedro vê os irmãos, a mulher e os filhos definharem e morrerem de fome, tendo ao lado da sua roça a imensidão de terras do coronel e as criações pastando com fartura. Neste ponto, o narrador justifica ao leitor o deslocamento do sertanejo ingênuo para a subversão, assolado por uma crise dos seus valores morais que se tornar verossímil porque atribui à vergonha do sertanejo por não poder cumprir seus compromissos o seu questionamento da realidade. Por causa da fome dos filhos, Pedro abate uma ovelha velha do rebanho do coronel, mas o fazendeiro impassível o repreende:

- Você me roubou, Pedro Macário. Você é ladrão!

- Não sou, coronel. Vosmicê sabe bem. Juro pelo Bom Jesus da Lapa. Ia lhe contar. Contar à comadre, também.

- Depois do roubo? Não adiantava, compadre. Você pegou no alheio. Você é ladrão (SÃO PAULO: 1969, 98).

O diálogo acima prepara a tensão em que a narrativa só deixa duas saídas para o personagem oprimido: ou ele se penitencia resignado ao coronel, 
perdendo de vez sua fortaleza moral, para preservar a integridade física, ou parte para a reação à afronta, recuperando a moral com a certeza do desvio da ordem social da atitude, com a prisão ou cangaço como destino.

Os elementos envolvidos, resignação ou revolução, não caracterizam neles mesmos uma tese e antítese dialética da condição cultural do personagem sertanejo, como superficialmente aparece em outras narrativas de cunho romântico ou naturalista. O maniqueísmo clássico colocaria Fabiano, de Vidas Secas, como resignado diante do mesmo dilema, assim como o Manuel, em Deus e o diabo na terra do sol, seria o revolucionário, por assassinar o coronel. As fórmulas dicotômicas reduzem a potência de deslocamento ambíguo e nômade dos personagens. Olney parece perceber isto na leitura enviesada que faz dos personagens mais famosos da tradição regionalista sertaneja. Ele reconstrói a dialética que remete ao dilaceramento dos personagens, chamando a atenção do leitor para a linguagem como um devir de uma subjetividade inacabada. A irracionalidade incontrolável e imprevisível do personagem fruto das contradições da cultura em conflito com a realidade impõe a necessidade de uma ficção humanista mais radical, que incomode o leitor pela exposição direta da violência que simetriza e iguala o vencedor e o vencido. Ou seja, nasce a ação revolucionária tanto da resignação quanto da ação, como poder de resistência diante de circunstância de mera força física.

O caráter romântico ou naturalista da narrativa revela-se no argumento dramático dos textos de Olney, mas o leitor deve observar a obra atravessada por uma estética da violência, que articula ao caráter conservador do tema uma política da violência narrativa que incorpora corte, montagens e imagens do filme de western ao enredo literário. O conto de Olney São Paulo problematiza este jogo, após a tensão criada entre Pedro Macário e o coronel Tibúcio, quando a expectativa do leitor vai se deslocando para o campo político conservador ou revolucionário, a partir de intervenção do narrador, que toma a voz do personagem sertanejo:

Pedro Macário de Oliveira, sertanejo calejado de desventuras, montando o seu cavalo velho, zargo e ronceiro, olhava o campo de sisal do coronel Tibúcio e pensava no mundo. Naquele mundo povoado de desgraçados, onde a única esperança de ventura, era a morte. Naquele mundo onde apareceria, para completar o seu infortúnio, o rosto do coronel Tibúcio, severo e frio, a chamar os filhos, os irmãos e os compadres, de miseráveis, de desgraçados, de ladrões (Idem). 
As reflexões sobre a situação moral do personagem sertanejo, "que nunca tivera razão" (Idem: 99), dão ao leitor indícios de um provável desfecho para o impasse. $\mathrm{O}$ conto cresce em expectativa quando os comentários do narrador, intruso, mesclam-se ao discurso interior de Pedro Macário, preparando a saída pela ação. Morre sua mulher, morrem os seus filhos e ele mergulha nas lembranças dos jagunços mortos, do Conselheiro e tantos outros sertanejos. A sua decisão é tomada pela "dor do ódio, a dor da vingança, a dor de um homem desamparado por Deus e por todos os homens da terra" (Idem: 104). Ele monta a cavalo e parte para a fazenda do coronel, onde se dá uma montagem de choque inesperada pelo leitor que optou pela ação revolucionária, como resposta ao realismo socialista de esquerda que sugere as etapas de consciência ao triunfo do herói. Quando a narrativa se encaminha para o desfecho da ação de vingança do sertanejo contra o coronel, num repente, o narrador encerra a vida do herói Pedro Macário, que: "Nem bem chegara à cancela da "Aroeira", um tiro de espingarda (...) jogara-o em cima das pontiagudas moitas de sisal" (Idem: 105). Há um corte no interior da cena e o narrador insere com ironia o comentário do coronel Tibúcio sobre quem seria o responsável pelo crime: “- Algum caçador descuidado(...)" (Idem, ibidem).

A morte de Pedro Macário destrói a expectativa heróica do épico, mas o conto encerra o relato sugerindo a utopia como mito do beato "tuberculoso, barbudo e feio", que grita a verdade sobre a morte do sertanejo contra 0 vento que "tenta sufocar sua voz" (Idem, 105-106).

O conto de tema sertanejo apresenta todos os elementos da tradição do regionalismo. A escrita de Olney se faz segura e corrente, jogando com as peculiaridades narradas: a presença dos mitos, do vocabulário, das sensações táteis e visuais, deslocando a narrativa do conto da sensação ingênua do romantismo e do determinismo naturalista, a fim de lançar o contexto sócio-político para o narrador impotente diante do desfecho. Ele preserva a tradição da narrativa regionalista sob um olhar que insere questões nacionais e ideológicas da contemporaneidade do conto, como a forma da narrativa cinematográfica que desperta no leitor outra sensibilidade sobre a narrativa de ação que a imagem em movimento já havia habituado ao novo público leitor experimentado nos cinemas de aventura.

A tendência para novos elementos descritivos na narrativa de Olney São Paulo está muito clara nos contos da primeira parte do livro Antevéspera e Canto do Sol, em que há uma colagem de neo-realismo, surrealismo e experiência concretista na forma cinematográfica de descrever os personagens e 
cenários. O lugar ao mesmo tempo é um não-lugar numa alegoria calcada no racionalismo e paradoxalmente no irracionalismo das tradições narrativas populares que o cinema incorpora e redimensiona em seu imaginário. $\mathrm{O}$ conteúdo é o mesmo e é outro em relação à tradição modernista, pois ele se dispersa no relato ora lento ora de movimentos bruscos, que coloca o leitor em certo transe dos experimentos da literatura brasileira pós- 1950 .

Há outros aspectos que aproximam em semelhança e diferença o conto de Olney da tradição do regionalismo sertanejo. Ele sugere um equilíbrio entre a visão de um intelectual leitor de uma tradição literária e um narrador comprometido com a própria memória. Este equilíbrio redefine sua opção ética e estética em conjuntura política que demanda certo engajamento cultural da escritura. A experiência da obra do escritor de Riachão do Jacuípe tem forte relação com a produção cinematográfica da época a partir do momento em que ele mesmo retoma seus contos posteriormente e converte-os de escrita literária em roteiros de cinema, fazendo o tecido narrativo transitar por dentro do discurso literário e cinematográfico nacional. Os contos do seu livro trazem uma visibilidade cinematográfica perfeita, na maioria das vezes iniciando o texto verbal com a técnica de cinema do plano geral: "outrora, onde a catinga de porco, a malva branca e a macambira se balançavam com o vento quente, vindo de um fim de mundo, surge agora o sisal (...)", A Rebelião e o Vento (Idem: 97); "Norteada de serras, num perder de vistas de catingas cinzas-azuis, distantes - a vila", O Destacamento (Idem: 109); "A procissão, em ritmo lento de marcha fúnebre, seguia o seu caminho de via sacra, por entre aquela rua triste de casas velhas, carcomidas por séculos", $O A B C$ do Enforcado (Idem: 137); e "A praça, nas noites de festa, se enchia de povo, que em volta do coreto, ficava a ouvir o desafio das filarmônicas", em A Transcendente Anunciação da Rosa (Idem: 149), são exemplos do estilo narrativo que agencia no texto literário o imaginário cinematográfico.

A identificação da linguagem fílmica na forma narrativa dos contos, que aparece em vários outros escritores, não pode ser desprezada pela crítica contemporânea, pois abre uma série de questões pertinentes ao imaginário cultural e ficcional do narrador da literatura na atualidade. $\mathrm{O}$ crítico não questiona a intencionalidade ou não do estilo do escritor, mas investiga as intensidades de sentidos no jogo de formas da linguagem cinematográfica na literatura. Nos contos de Olney, os planos gerais do início dos enredos reforçam outras técnicas do cinema no desenvolvimento da ação narrativa. Por exemplo, cada parágrafo dos contos fecha a imagem como se fosse uma 
truncagem de seqüências ligadas pelos sentidos e não pelas conjunções gramaticais, iniciando outra nova ação em cada parágrafo-seqüência sucessivamente. Isto aparece intensamente no conto O Destacamento. Os parágrafos abrem um conjunto de cenas que visivelmente se encerram para ressurgir como continuidade em nova imagem, dando a sensação de plano-seqüência ao relato: “"Cravo Santo” usa um chapéu de couro batido à testa (...)", em seguida, "A estação, parada rápida do trem(...), para em outro parágrafo, "Cabo Samburá espera o trem(...)”(Idem: 109), e (...) “Em um entardecer à beira do riacho, que circunda as ruas da vila, os tristes olhos de Teresa"(...) (Idem: 110), enfim, o conto se desdobra em oito partes, repetindo essa estrutura de montagem.

Cada parágrafo ocupa-se de uma seqüência bem recortada e definida, para num processo de escrita por montagem fazer o encadeamento linear da trama, dando conta da forma tradicional da literatura, mas crivada pela novidade do sistema de narrar cinematográfico. Com este movimento, mesmo os parágrafos de ações interiores dos personagens ganham visibilidade e concisão, saltando das páginas como imagens em movimento. Importa ao leitor saber se esta organização formal traz em si os modelos de representações mentais condicionadas pelo contexto da sociedade na qual a obra foi produzida. Para Antonio Candido (2000:153), toda leitura crítica de obra literária precisa levar em conta:

um nível de realidade e um nível de elaboração da realidade; e também a diferença de perspectiva dos contemporâneos da obra, inclusive o próprio autor, e a da posteridade que ela suscita, determinando variações históricas de função numa estrutura que permanece esteticamente invariável.

São pequenos traços e circunstâncias que mobilizam a recepção da obra de Olney, e, conforme o crítico observa no fragmento acima, é preciso interpretar os detalhes, articulando as teorias mais apropriadas para fazer dialogar a recepção de hoje com os aspectos formais e circunstanciais que o autor conferiu a sua obra no passado.

Verificando as peculiaridades da literatura de Olney São Paulo, construímos nossa provisória tese sobre a sua "literatura menor" neste ensaio, ou seja, a de verificar o paradoxo da relação entre tradição e ruptura no seu texto literário marcado pelo imaginário tradicional, mas cortado pela tendência do diálogo moderno entre o sentido literário e o cinematográfico. Por outro lado, é importante demarcar o quão problemático é o seu distanciamento e aproximação da estética nova do cinema e da literatura brasileira à época dos seus escritos. 
Olney São Paulo tem seus primeiros contatos práticos com o cinema novo nacional via Alex Viany, Glauber Rocha e Nelson Pereira dos Santos, em filmagens realizadas no início da década de 1960, em Feira de Santana. Contudo, o seu compromisso de engajamento cultural remonta a sua formação literária transformada num jeito singular de realizar documentos e ficções cinematográficas, inclusive as adaptações e os diálogos com obras de Jorge Amado, Cyro de Carvalho e Adonias Filho, entre outros escritores. Os seus documentários retomam o imaginário e a mitologia sertaneja dos seus contos, a exemplo de Sob o ditame de Rude Almajesto: Sinais de Chuva (1976), adaptação de uma crônica do escritor conterrâneo Eurico Alves, que narra as tradições camponesas da previsão de chuva no sertão. Ainda neste filme da obra madura de Olney percebemos o recurso inventado por ele nas narrativas literárias, o de retratar os aspectos clássicos da tradição documental do registro da memória popular, mas numa forma cinematográfica de conseqüências fundamentais para o novo documentarismo brasileiro como ensaio antropológico. Os problemas eventuais da produção de baixo orçamento repercutiam no uso da luz direta, do som captado in loco com ruídos, nos enquadramentos desfocados e nos planos com câmera na mão, que redimensionam a objetiva clássica do documentário num resultado plástico quase sem precedentes no cinema nacional.

Neste sentido da dialética entre o clássico e o novo, entramos em um campo de discussão ideológica no interior da crítica da literatura e do cinema brasileiro, que, a partir dos anos 1950 é marcada pelos desdobramentos do modernismo. No cinema, um exemplo é o embate entre os cinemanovistas e a tradição representada pela Vera Cruz, com o sucesso de O Cangaceiro (1953), de Lima Barreto, no que diz respeito ao tema tradicional do cangaço. A dramaturgia clássica da indústria melodramática de estilo hollywoodiano versus o cinemanovismo das gerações dos anos 1950/1960 enfraquecem a grande indústria com os modelos experimentais do neo-realismo italiano, da nouvelle vague francesa e dos cinemas novos pós-guerra.

Para avaliarmos a narrativa de Olney São Paulo nesse contexto é preciso flagrar o tensionamento entre criação literária e cinematográfica, buscando a sua formação de leitor e de realizador dessas linguagens, o que ainda é pouco estudado da perspectiva crítica contemporânea. A obra de Olney São Paulo, envolvida nos dilemas dos anos 1950/1960, apresenta-se ainda hoje como um importante traço da nossa história literária, cinematográfica e cultural recente. Ela resgata elementos da cultura local em seu conteúdo e é atravessada por uma crise formal que reflete o pensamento estético da 
época, ainda vivenciada atualmente nos laços entre o autor e o público, a partir da expansão dos meios de comunicação nos últimos 30 anos e da controvertida construção nesse período de um consumo de massa público hegemônico e de um discurso acadêmico contra-hegemônico, que atravessa as investigações sobre a arte nacional popular, principalmente no que tange à literatura e seus diálogos com o audiovisual e a comunicação massiva. Portanto, várias obras que foram recalcadas ou proibidas na construção do cânone e da figura do leitor ideal podem desvelar novas estratégias de reconhecimento de lugares e olhares para além da forma narrativa convencional.

O quase apagamento cultural de Olney tanto pode ser um descuido do leitor ao se desvencilhar do trauma da repressão militar, que envolveu o acontecimento do seu filme Manhã Cinzenta, quanto pode estar ligado às contradições do cânone nacional estabelecido por modelos centrados em certas categorias que excluem as obras "menores". Além disso, investigar o ocaso da narrativa de Olney São Paulo pode desvelar os falsos problemas advindos da sua visão de mundo literária contraditória entre contos de um imaginário altamente moderno e outros que retomam a tradição regionalista, conforme ele segmenta no próprio livro publicado, dividido em duas partes: Antevéspera, que contém contos de uma narrativa radicalmente inovadora na simbologia urbana e na linguagem atravessada por intertextualidade e interdiscursividade; e o Canto do Sol, que reúne os contos de tema do sertão. No entanto, as duas partes se suplementam como nova escritura literária, como fica claro na análise dos contos da parte considerada da narrativa tradicional.

Antevéspera e o Canto do Sol dialoga potencialmente com a produção literária brasileira dos anos 1950/1960, propondo questões éticas e estéticas em torno do tema rural e urbano fragmentados, trazendo o diálogo com correntes narrativas do pós-guerra vinculadas ao engajamento filosófico e social do autor, do leitor e da obra. A memória regionalista conservadora é acionada, dando conta de momento histórico literário em crise de valores e de formas, o que demarca a própria instabilidade da cultura brasileira em contato com novas tradições de expressão inauguradas pelos modernistas, mas ainda inesgotadas em seus potenciais estilísticos, como é o caso da literatura cinematográfica. Este hibridismo formal reflete a própria mestiçagem cultural do país, fazendo coincidir mais uma vez o conteúdo com a forma de expressão, conforme o radical pensamento da ideologia nacionalpopular e das teorias artísticas da época, de acordo com os manifestos 
das vanguardas literárias e cinemanovistas, que investiam nas estratégias de comunicação para formar novos públicos comprometidos, no cerne da indústria cultural. Para isto, os escritores e cineastas desdobram as conquistas das narrativas populares do romance regionalista. Como diz Antonio Candido (2000: 125), após os anos 1930, quando o Brasil consegue ampliar o público da literatura para além dos diletantes e "conhecedores", abre-se logo depois uma nova crise com os meios de comunicação:

Viu-se então que no momento em que a literatura brasileira conseguia forjar uma certa tradição literária, criar um certo sistema expressivo que a ligava ao passado e abria caminhos para o futuro - neste momento as tradições literárias começavam a não mais funcionar como estimulante. Com efeito, as formas escritas de expressão entravam em relativa crise, ante a concorrência de meios expressivos novos, ou novamente reequipados, para nós - como o rádio, o cinema, o teatro atual, as histórias em quadrinhos.

Enfim, olhando em conjunto a obra de Olney São Paulo, percebe-se que ela articula a literatura e o cinema na sua forma escrita ou filmada, assim como o conteúdo do regionalismo sertanejo articula o viés da tradição popular da literatura de 1930 colada a matrizes fragmentadas de personagens urbanos em contraponto aos valores rurais. De certa forma, é uma literatura permeada de dilemas do imaginário cinematográfico, que traz novas expectativas para a literatura brasileira, o que corresponde ao que disse Guimarães Rosa à época: “ - A literatura desaparecerá no Brasil. Só teremos música e cinema (apud NAGIB, 1996: 71)”. Essa afirmação não significa a extinção do escritor ou o desaparecimento do texto literário, mas a transformação da escrita e o retorno ao projeto modernista sobre novas formas de expressão literária. Também Jorge Amado dissera nos anos 1960 que no Brasil desapareciam os narradores literários porque os "jovens artistas são músicos ou cineastas (Idem)."

A possibilidade da hipótese apresentada inicialmente, ou seja, que a narrativa literária de Olney São Paulo assimila a dinâmica cinematográfica no texto ao mesmo tempo em que há um distanciamento da política mais central da vanguarda realista socialista, talvez seja fruto consciente e inconsciente do autor em busca de estratégias para lidar com as contradições sociais, políticas e culturais do país outro que ele apreendeu e reconstruiu das imagens regionalistas e também incorporou da experiência própria de sertanejo. O limite da convergência entre vida e arte, literatura e cinema, tema tradicional do sertanejo e fragmentações urbanas, ou ainda entre a 
experiência social do autor e a coerência estética da sua formação modernista desdobrada, todas estas evidências validam novos estudos contemporâneos sobre a produção literária e cinematográfica de Olney São Paulo.

\section{REFERÊNCIAS BIBLIOGRÁFICAS:}

BENJAMIN, Walter. O narrador - Considerações sobre a obra de Nicolai Leskov. In: . Obras escolhidas - vol 1. São Paulo: Brasiliense, 1993.

BOSI, Alfredo. Reflexões sobre a arte. São Paulo: Ática, 1986.

CANDIDO, Antonio. Literatura e Sociedade. São Paulo: Publifolha, 2000.

DELEUZE, Gilles. Sobre a Imagem-Tempo. In: . Conversações.

Rio de Janeiro: Editora 34, 1992.

NAGIB, Lúcia. O sertão está em toda parte - Glauber Rocha e a Literatura Oral. In: Revista Imagens, n 6, Unicamp, 1996, p. 71.

SANTIAGO, Silviano. O Cosmopolitismo do Pobre - Crítica Literária e Crítica Cultural. Belo Horizonte: Editora UFMG, 2004.

SÃO PAULO, Olney. A Antevéspera e o Canto do Sol - Contos e Novelas. Rio de Janeiro: José Álvaro Editor, 1969. 
